\title{
The Novel Design and Manufacturing Technology of Densified RDF from Reclaimed Landfill without a Mixing Binding Agent Using a Hydraulic Hot Pressing Machine
}

\author{
Somrat Kerdsuwan, Pubet Meenaroch and Thitaaus Chalermcharoenrat
}

The Waste Incineration Research Center, Department of Mechanical and Aerospace Engineering, Faculty of Engineering, Science and Technology Research Institute, King Mongkut's University of Technology North Bangkok, Bangkok, Thailand

\begin{abstract}
The manufacturing of RDF (Refuse Derived Fuel) from a conventional cold press extrusion machine is not suitable for producing RDF from reclaimed landfill since it is not identical in shape and form after production due to the swelling of the plastic fraction contained inside the reclaimed landfill and hence needs a very high compression force. Moreover, a binder agent is needed in order to keep the RDF in a similar shape and form. A novel design and manufacturing technology for a hydraulic hot pressing machine has been established and can produce high-quality RDF without any binder. The two electrical heaters are installed at the inner core and on the surface of the mold. The compression force on the mold is performed by a hydraulic jack. In addition, a newly-designed locking plate system which is designed by a slider to open and close along the paired horizontal slots, can reduce the cycle time of the manufacturing process and yield higher productivity. The testing properties of the RDF produced by the novel hydraulic hot pressing machine include the examination of size, shape, weight, unit density, bulk density, compression strength, moisture content, and heating value. The results showed that the RDF is suitable to be used as feedstock in an incinerator or gasifier to produce green and clean energy from reclaimed landfill.
\end{abstract}

\section{Introduction}

Nowadays, landfill, which is regraded as a simplified technology for the disposal of municipal solid waste (MSW) in many countries, is widely used [1]. However, due to a huge amount of MSW, most of it has been disposed by open dumps, which causes subsequent problems, for instance, health problems, leachate, requirement of land space, etc. Consequently, it is necessary to reclaim land for reuse. The residual left after the urban mining process is called reclaim landfill, which needs a suitable disposal technology that can recover green and clean energy effectively and sustainablility. Incineration or gasification technology, which is a thermal treatment option, can be considered as an alternative choice for reducing the mass and volume of reclaimed landfill by burning and can convert it into alternative green and clean energy. Considering the combustible fraction of reclaimed landfill, which is mostly plastic and paper, it can be used as feedstock with an incinerator or gasifier. However, in order to improve its efficiency, reclaimed landfill should be converted into RDF (Refuse Derived Fuel), and consequently, its quality will improve, including an increase in bulk density, low moisture, high heating value, etc. [2]. Normally, the RDF can be prepared with three main technologies, e.g. a piston press, a screw press, and a pelletizing method. There can be in several forms, such as briquettes and pellets, which depend on the mold used. Previously, the technology of compressed RDF used the hydraulic hot pressing system while the sample was compressed, the mold cover or locking plate was locked by a bolt. The heater was only installed at the surface of the mold. Hence, the RDF that is produced from this machine easily cracks because it has not been heated at the inner core [3]. The aim of this work is to redesign and manufacture the hydraulic hot pressing machine to overcome this difficulty and manufacture of RDF from reclaimed landfill without a mixing biding agent.

\section{Review of RDF production}

The classification of RDFs can be divided into 7 groups as shown in Table 1. Each of these RDFs has different properties. RDF-1 is MSW that has been sorted out to remove oversized bulky fraction only. To use MSW as fuel for a fluidized-bed combustion system, the combustible waste is ground to coarse particle size of approximately 6 cubic inches or less and it is classified as RDF-2. RDF-3 are the removal of the incombustible fraction (metal, glass, and other entrained inorganics), then will be cut in size until the particle size is smaller than 2 inches. RDF-4 is combustible waste in the form of powder. RDF-5 is highly-densified fuel (more than 600 $\mathrm{kg} / \mathrm{m}^{3}$ in density) by compression and appears in several 
forms such as pellets, slugs, cubettes, briquettes or similar forms. The benefits of compression are increased bulk density, low moisture, high heating value, and being easy to transport. The combustible waste processed into a liquid or in the form of slurry is called RDF-6. Finally, RDF-7 is the combustible fuel in the form of gaseous which is produced by the gasification process [2].

The next consideration is the high operating cost due to the use of an additional fuel burners in the primary combustion chamber. The purpose of this burner is to sustain the desired combustion temperature in the chamber when burning high-moisture waste content, especially with wet fraction MSW (food waste, vegetation waste, etc.) The more that this additional burner is used, the more additional fuel must be used (diesel oil, for example), which results in high operating costs. In order to overcome this, the less use or even no use of the burner muse be taken into account, even by improving the combustion process by using a novel design of combustion air distribution or by mixing the characteristics of waste and air.

Table 1. ASTM classification of RDFs [2]

\begin{tabular}{|c|c|l|}
\hline Class & Form & \multicolumn{1}{c|}{ Description } \\
\hline $\begin{array}{c}\text { 1. RDF-1 } \\
\text { (MSW) }\end{array}$ & Raw & $\begin{array}{l}\text { Municipal solid waste with } \\
\text { minimal processing to remove } \\
\text { oversized bulky waste }\end{array}$ \\
\hline $\begin{array}{c}\text { 2. RDF-2 } \\
\text { (C-RDF) }\end{array}$ & Coarse & $\begin{array}{l}\text { MSW processed to coarse particle } \\
\text { size with or without ferrous metal } \\
\text { separation such that 95\% by } \\
\text { weight passes through a 6 in. } \\
\text { square mesh screen }\end{array}$ \\
\hline $\begin{array}{c}\text { 3. RDF-3 } \\
\text { (f-RDF) }\end{array}$ & Fluff & $\begin{array}{l}\text { Shredded fuel derived from MSW } \\
\text { processed for the removal of metal, } \\
\text { glass and other entrained } \\
\text { inorganics. The particle size of this } \\
\text { material is such that 95\% by } \\
\text { weight passes through a 2 in. } \\
\text { square mesh screen. }\end{array}$ \\
\hline $\begin{array}{l}\text { 4. RDF-4 } \\
\text { (p-RDF) }\end{array}$ & Powder & $\begin{array}{l}\text { Combustible waste fraction } \\
\text { processed into powdered form } \\
\text { such that 95\% by weight passes } \\
\text { through a 10 mesh screen (0.035 } \\
\text { in. square) }\end{array}$ \\
\hline $\begin{array}{l}\text { 5. RDF-5 } \\
\text { (d-RDF) }\end{array}$ & Densified & $\begin{array}{l}\text { Combustible waste fraction } \\
\text { densified (compressed) into } \\
\text { pellets, slugs, cubettes, briquettes } \\
\text { or similar forms }\end{array}$ \\
\hline 6. RDF-6 & Liquid & $\begin{array}{l}\text { Combustible waste fraction } \\
\text { processed into a liquid fuel }\end{array}$ \\
\hline 7. RDF-7 & Gas & $\begin{array}{l}\text { Combustible waste fraction } \\
\text { processed into gaseous fuel }\end{array}$ \\
\hline
\end{tabular}

Conventionally, the extruded machine can be used to prepare RDF-5. Reclaimed landfill from old dumpsite landfill urban mining mainly contsisting of paper and plastic is compressed using a screw extrusion machine [4], as shown in Fig. 1. The length, height, and width of the screw extrusion body used in this study were 800, 1000, and $500 \mathrm{~mm}$, respectively. The other parts were a feeding hopper, a 7500 watt motor, a 300 watt heater coil, a feeding screw, and a die (inner diameter of $50 \mathrm{~mm}$ ). To produce RDF, the MSW, which is fed at the rate 200-300 $\mathrm{kg} / \mathrm{hr}$ into the hopper, moves down into the feeding screw connected to the motor and compresses the MSW in the die. At the same time, the heater is operated at $300^{\circ} \mathrm{C}$ in order to melt the fraction of plasstic. Finally, the extruded $\mathrm{RDF}$ is manually cut into $50-60 \mathrm{~mm}$ lengths.

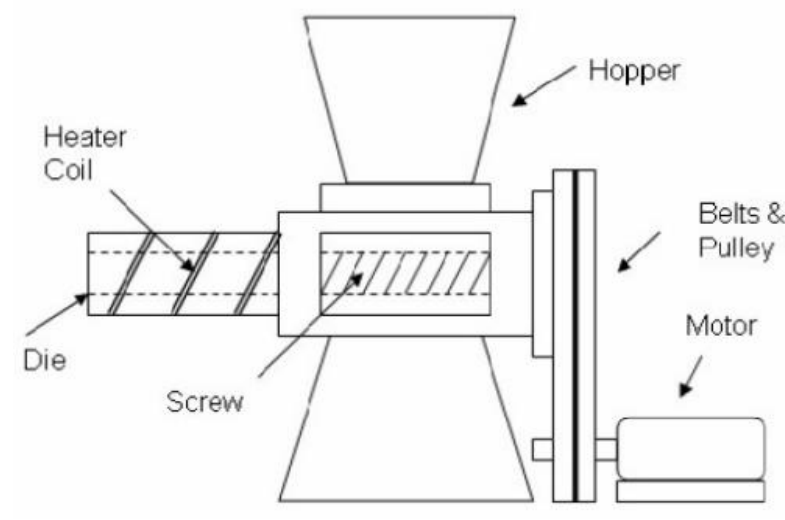

Figure 1. Screw extrusion machine with a heater at the die [4]

Nevertheless, the products produced by the screw extrusion machine are not of the same size or shape because the compressed RDF swells at the end of the extrusion die. Morover, the screw extrusion system cannot control the mixing ratio of RDF composition accurately and additionally the heat generated in the extrusion machine causes the plastic to melt; thus, some volatile matter is released, resulting in lowering the heating value of the fuel [5]. Therefore, the hydraulic hot pressing machine can be considered a way to overcome this disadvantage. This technique helps with the production of RDF-5 from reclaimed landfill that is more stable in size and shape.

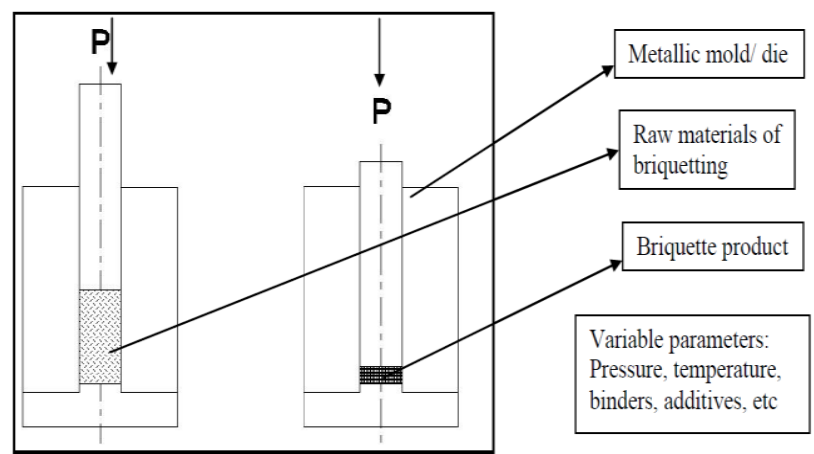

Figure 2. Assembly drawing of a conventional piston press densification machine [7]

\section{Innovative design of a hydraulic hot pressing machine without using mixing binder}

The different densification technologies of pressing machines can be classified according to several determining factors, including applied compression pressure, operating condition, and the feeding mode of operation. The applied compression pressure consists of low pressure (up to $5 \mathrm{MPa}$ ), intermediate pressure (5-100 $\mathrm{MPa}$ ), and high pressure (above $100 \mathrm{MPa}$ ). The operating conditions are hot and high pressure densification, and 
cold and low pressure densification where the feeding mode of the operation is batch and continuous [6]. The conventional piston press densification machine (Fig. 2) has been designed to produce RDF-5 in a cylindrical briquette shape without a central hole. The operating condition is a batch operation with the cold compress of low pressure force applied to loosen the raw materials together with a binder agent into a mold in order to achieve a completely solid uniform shape of the mold after removal of the compression force.

The conceptual design of the novel hydraulic hot pressing machine presented in this study is given in Fig. 3 and Fig. 4. This new design can produce RDF-5 from reclaimed landfill in cylindrical briquette shape with or without a central hole. The operating condition is the hot compress force applied to loosen the raw materials of the reclaimed landfill without a binder agent in the mold to get a completely solid uniform shape of the mold with a central hole after removal of the compression force based on the batch operation mode. The RDF-5 in the cylindrical briquette shape with the central hole provides better combustion characteristics due to the larger specific area and because of the high combustion rate. In addition, the newly-designed locking plate system which is designed by the slider to open and closed along the paired horizontal slots can reduce the cycle time of the manufacturing process and yield higher productivity.

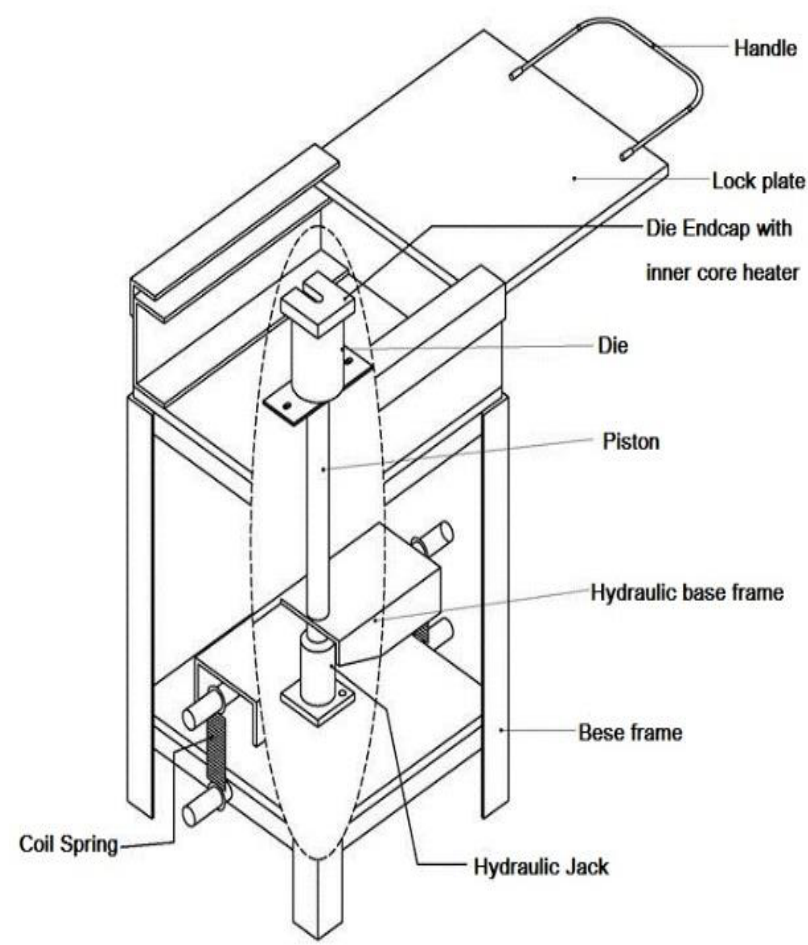

Figure 3. Conceptual design of a novel hydraulic hot pressing machine

The hydraulic jack can generate a compression force of approximately $11 \mathrm{MPa}$ inside the mold cavity. The heater was installed at the inner core in order to apply heat to the surface of the central hole area and the entire surface of the mold. The machine is made of steel with a dimension of $300 \mathrm{~mm}$ in width, $300 \mathrm{~mm}$ in length, and $580 \mathrm{~mm}$ in height. The mold to produce the RDF-5 is of a cylindrical shape with a central hole inner diameter of 48 $\mathrm{mm}$ and a length of $100 \mathrm{~mm}$. The pressing unit has a hydraulic piston stoke of $750 \mathrm{~mm}$. In addition, the elctrical power of the heater capacity applied to the entire outer mold surface is 300 watts and can sustain an operating temperature of $120^{\circ} \mathrm{C}$. The electrical heater power at the inner core of the mold is 200 watts with an equal operating temperature on the outer surface. The compressing time holds for 30 seconds per batch. Reclaimed landfill is put inside the mold, then a piston is compressed with the hydraulic jack. While it is compressed, the elctric heater switches on to melt the plastic fraction inside the reclaimed landfill at the outer surface and in the central hole area. The prototype machine can produce molding RDF-5 from reclaimed landfill which contains plastic of more than $50 \%$-wt. and bulk density higher than $600 \mathrm{~kg} / \mathrm{m}^{3}$ [8]. The production capacity of this machine is $1.2 \mathrm{~kg} / \mathrm{hr}$. The results of the physical and chemical properties of RDF-5 produced from the prototype of the hydraulic piston hot press densification machine are shown in [9].

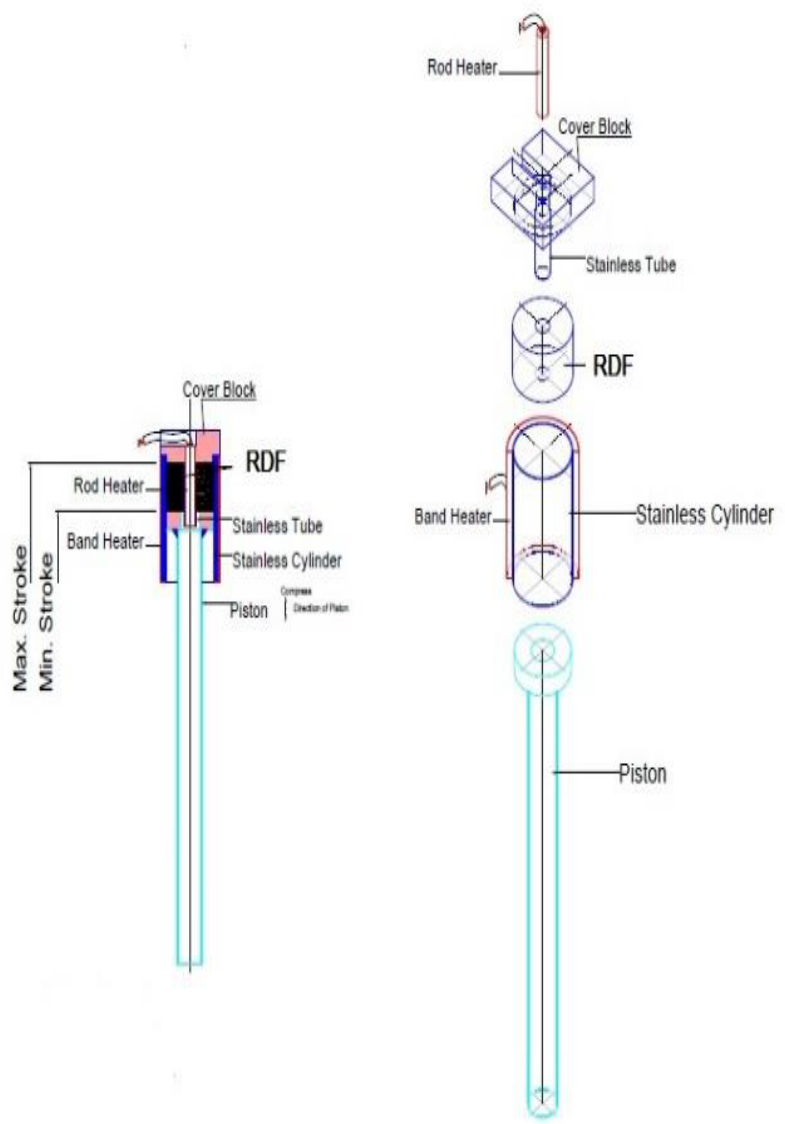

Figure 4. Assembly drawing of a novel hydraulic hot pressing machine

\section{Summary}

The novel hydraulic hot pressing machine in the present study was designed and manufactured in order to overcome the difficulty in producing RDF from reclaimed landfill, which cannot be done in using a conventional cold press densification machine. The RDF produced using the novel machine is similar in shape and 
form, with high bulk density and no use of any binder agent. The test of the physical and chemical properties of the RDF demonstrated that it is suitable to be used as feedstock in an incinerator or gasifier to produce green and clean energy from reclaimed landfill.

\section{References}

1. Pollution Control Department (PCD), Municipal Solid Waste Composition Survey and Analysis Project in Thailand: Final Report, Thailand: Pollution Control Department, (2015)

2. Robert E. Sommerlad, W. Randall Seeker, Abraham Finkelstein, James D. Kilgroe, Environmental Characterization of Refuse Derived Fuel Incinerator Technology, 1988 National Waste Processing Conference, Pennsylvania, (1998)

3. Tawach Prechthai, Maddala Padmasri, Chettiyappan, Quality Assessment of Mined MSW from and Open Dumpsite for Recycling Potential, Conservation and Recycling, vol. 53, pp. 70-78, (2008)

4. A.B. Nasrin, A.N. Ma, Y.M. Choo, S. Mohamad, M.H. Rohaya, A. Azali and Z.Zainal, Oil Palm Biomass as Potential Substitution Raw Materials for Commercial Biomass Briquettes Production,
American Journal of Applied Sciences, vol. 5, pp 179-183, (2008)

5. Kejian Wang, Description of Extrude Swell for Polymer Nanocomposites, Materials, vol. 3, pp. 386400, (2010)

6. United Nations Environmental Programme, Technologies for Converting Waste Agricultural Biomass to Energy, Division of Technology, Industry and Economics, International Environmental Technology Centre Osaka, (June 2013)

7. Ramesh M. Singh, Biobriquetting in Nepal - Scope and Potentials : a Review, Engineering and Technology, vol. 9, pp. 104-120, (2013)

8. Aatonio C. Caputo, Pacifico M. Pelagagge, $R D F$ Production Plants: I Design and Costs, Applied Thermal Engineering, vol. 22, pp. 423-437, (2002)

9. Somboon Chalermcharoenrat, Nuth Sirirermrux, Krongkaew Laohalidanond, Somrat Kerdsuwan, Optimization of the Production of Densified RDF from Reclaimed Landfill without Mixing Binding Agent Using Hydraulic Hot Pressing Machine, 2014 the 5th TSME International Conference on Mechanical Engineering, Chiang Mai, (2014) 